JGG 2020;68:204-211

doi: 10.36150/2499-6564-253

\title{
A survey of knowledge, attitude and practice of the older people about COVID-19 pandemic in Isfahan, Iran
}

\author{
Mohammad R. Maracy ${ }^{1}$, Majid Rahimi², Roohangiz Alirezaei Shahraki \\ ${ }^{1}$ Department of Epidemiology \& Biostatistics, School of Public Health, Isfahan University of Medical \\ Sciences,Isfahan, Iran; ${ }^{2}$ Department of Health Education and Promotion, School of Health, Isfahan \\ University of Medical Sciences, Isfahan, Iran; ${ }^{3}$ MSc of Aging Health, Amirhamzeh Health Center,, \\ Isfahan University of Medical Sciences, Isfahan, Iran
}

Received: August 11, 2020

Accepted: November 17, 2020

\section{Correspondence \\ Majid Rahimi \\ Department of Health Education and Promotion, School of Health, Isfahan University of Medical Sciences, Hezar-Jarib Street, Azadi Square, Isfahan, Iran, Postal Code: 81746-73461 \\ E-mail: majidnh79@gmail.com}

\section{Conflict of interest}

The Authors declare no conflict of interest

How to cite this article: Maracy MR, Rahimi M, Shahraki RA. A survey of knowledge, attitude and practice of the older people about COVID-19 pandemic in Isfahan, Iran. Journal of Gerontology and Geriatrics 2020;68:204-11. https:// doi.org/10.36150/2499-6564-253

(C) Copyright by Società Italiana di Gerontologia e Geriatria (SIGG)

\section{(c) (1) $(9)$}

\section{OPEN ACCESS}

This is an open access article distributed in accordance with the CC-BY-NC-ND (Creative Commons Attribution-NonCommercial-NoDerivatives 4.0 International) license. The article can be used by giving appropriate credit and mentioning the license, but only for non-commercial purposes and only in the original version. For further information: https://creativecommons.org/licenses/by-nc-nd/4.0/deed.en
Objectives. Clinical evidence suggests that the COVID-19 disease is more severe in the endangered populations. The purpose of this study was to investigate knowledge, attitude and practice of older people in Iran toward COVID-19 disease as a high risk group.

Methods. A cross sectional study of 249 older people was conducted, using a researcher-made questionnaire. Data analysis was performed using descriptive and analytical statistics, using generalized linear model using the Gamma probability distribution model.

Results. Mean scores of knowledge, attitude and practice of the older people were $92.3 \pm 10.8,89.1 \pm 14.3$ and $90.4 \pm 13.4$ respectively and were not significantly different from the sex and history of underlying diseases $(p>0.05)$. At generalized linear model there were no significant relationship between the older people age and their mean scores of knowledge $(p>0.05)$, but significant relationship between level of education and knowledge score $(p<0.001)$ and age and attitude, and age and practice $(p<0.5)$, adjusted for age $>80$ years.

Conclusions. This study is among the first to assess knowledge, attitudes and practice of older people toward the COVID-19 pandemic in Iran. The results indicated that the general education about the disease and follow-up of responsible organizations has been effective and these interventions need to continue.

Key words: knowledge, attitude, practice, older people, COVID-19

\section{INTRODUCTION}

The outbreak of the coronavirus in China caused a worldwide alert in December 2019, and the disease was called COVID-19 ${ }^{1}$. Due to the rapid global spread of the disease in March 2020, the World Health Organization declared it the COVID-19 pandemic ${ }^{2}$. The spread of the disease has created a crisis in public health that is still ongoing expanding because of the strong dependence of countries in economic, social,and political fields ${ }^{3}$. In the Islamic Republic of Iran, the number of patients and deaths due to the disease is increasing rapidly, accordingly, prevention and control of the disease is one of the priorities of the Ministry of Health and Medical Education and has formed the National Anti-Corona Headquarters ${ }^{4}$. Before the present article, more than 670,000 people were infected in Iran and more than 37,500 people died from the disease, putting Iran in the fourteenth rank in the world ${ }^{5}$. 
The focus is on describing the clinical condition, determining severe cases of the disease, and treating the patients ${ }^{6}$. Clinical evidence suggests that the disease is more severe in older people or those with underlying diseases, such as diabetes, lung disease, and other chronic diseases ${ }^{7}$.

Common symptoms include fever, shortness of breath, and muscle aches, or fatigue. There may be also diarrhea and nausea at the onset of the disease before the onset of fever. Fever is the predominant symptom; and there are headache and bloody sputum in a small group of patients ${ }^{8}$. Sometimes, the patients are asymptomatic ${ }^{2}$. The difficulty in diagnosing for various reasons such as prolonged incubation period and the similarity of symptoms with colds and flu is a cause of the rapid global spread of the disease ${ }^{2,9}$. According to the Ministry of Health and Medical Education, the incidence of this disease is increasing in Iran. In Isfahan, the incidence of COVID-19 allocates for a high percentage in the whole of Iran with the patients' average age of $58{ }^{4}$.

Experiences of other viral corona epidemics such as the Middle East respiratory syndrome (MERS) and the influenza pandemic indicate that we urgently need to expand public health-related activities to shed light on the epidemiology of the new virus and found its potential effects, including the number of infected people, transferability and severity of its clinical symptoms ${ }^{6}$. Epidemiological methods focus on disease control to intending to to reduce transmission between humans, and animals to humans, rapid diagnosis of infectious diseases, effective measures to control infection, and tracking contacts ${ }^{10}$. Due to the high probability of infection, complications, and mortality in older people, it seems necessary to focus on health activities in this segment of society ${ }^{1}$. Therefore, we need to be more aware of older people's health status in this situation. The public's understanding of biological hazards plays an important role in responding to health crises, risk management ${ }^{11}$, and individual behavior ${ }^{12}$. In the last four decades, studies have been conducted on knowledge, attitudes, and practice as the main strategy of educational interventions to control respiratory diseases worldwide ${ }^{13}$, indicating the effects of knowledge, attitude, and practice levels in individuals on the adequacy of disease control and prevention, response to treatment and progress in increasing the individuals' levels of health ${ }^{14}$. Low levels of knowledge, attitude, and practice are the most important indicators of poor health, the ineffective performance of health-related care, declining screening rates, and unrealistic prevention behaviors in various infections in different locations ${ }^{15}$. Evidence suggests that misunderstandings and misconceptions about emerging infectious diseases have led to anxiety, disorder, and even extreme fear that in turn can worsen epidemic conditions ${ }^{16}$.

In this regard, the Ministry of Health has published guidelines in accordance with methods provided by the World Health Organization to prevent further spread of the disease that includes improving the level of health information, isolating patients, and avoiding close contact with other people ${ }^{4}$. Observance of hygiene depends on the level of awareness in older people about the necessary information. Older people's attitude is also effective in performing behaviors related to their health. On the other hand, the existence of contradictory information in various formal and informal networks, especially the virtual network, leads to the creation of different knowledge, attitudes, and practices in this field ${ }^{17}$.

Due to the relatively short time from the onset of the COVID-19 epidemic, there is little information about the knowledge, attitude, and practice of the older people as the riskiest segment of society. Due to extensive health centers across Iran and the special role of the centers in providing health services for older people, they seem to be the best places for collecting data on older people's knowledge, attitude, and practice about COVID-19. Therefore, the present study was designed and conducted to evaluate the older people's levels of knowledge, attitude, and practice about COVID-19 in Isfahan.

\section{METHODS}

The present cross-sectional study was conducted on the community-dwelling older people population of Isfahan. Inclusion criteria: age over 60 years; and desire to participate in the study; and responding to items of the questionnaire. Items of the questionnaire were asked by trained questioners in compliance with all health standards and physical distance.

It was sought to use the older people's comments belonging to all socio-economic groups living in Isfahan to increase the generalizability of the results of the evaluation study. To this end, the urban area of Isfahan was divided into three regions. The criterion for this division was a study according to 21 indices relating to urban development. Based on the results of this study, the city was divided into three regions, privileged, semiprivileged, and low-privileged ${ }^{13}$. After determining the boundaries of three regions, all health care centers located in each of the regions with low-privileged and privileged areas were considered as a cluster, and then a health center from each region was selected by a simple random method and was included in the study. (Imam Ali, Amir Hamzeh, and Molla Hadi Sabzevari centers). The criteria for inclusion in the study were the 
willingness to participate in the study and the ability to answer the questions in the questionnaire. The sample size was obtained to be 170 considering the 95\% confidence level and estimating the standard deviation of older people knowledge or attitude or practice scores by converting to a scale of 0 to 100 equal to one-sixth of the range of changes, and sampling error 2.5 by considering about $15 \%$ standard deviation. The sample size was obtained to be 255 considering the design effect of 1.5. Due to the prevalence of the disease and a reduction in the number of older people referred to health centers and the lack of permission to make phone calls to selected older people by chance, 85 older people who visited each of three centers, were equally selected by the convenience sampling and answered the questions after providing the informed consent. The scientific and ethical codes (IR.MUI.RESEARCH.REC.1398.829) and the license to start the project were obtained from the research and health deputy of Isfahan University of Medical Sciences to observe the ethical principles. At the beginning of the interview, the project purpose and ethical points such as free participation, the right to withdraw from the study, no need for a name, and confidentiality of information were explained for the participants.

The researcher-made questionnaire containing seventeen questions on a 5-point Likert scale was the research tool, which was used for assessing the knowledge, attitude, and practice of the older people with standard methods for preventing and treating COVID-19, in which the answers ranged from I strongly agree (score 5), I agree (score 4), I have no idea (score 3), I disagree (score 2), and I strongly disagree (score 1). At the first stage, the initial number of questions was based on the literature review and brainstorming; 17 questions about knowledge; and 10 questions about attitude and practice; and a total of 37 questions. After compiling the questionnaire, its face validity was measured by 20 healthy older people, and then their opinions were collected on the appropriateness, difficulty, relevance, and ambiguity of the questions; and necessary corrections were made to the questionnaire according to their opinions. Content validity (quantitative and qualitative) was performed according to the opinion of 14 faculty members in the fields of gerontology $(n=7)$, health education and promotion ( $n=5)$, and nursing $(n=2)$; and the Content Validity Indicator (CVI) was considered to be more than 0.79, and the Content Validity Ratio (CVR) was also greater than 0.51 based on the Lawshe table. Finally, questions of the knowledge section, including 7 questions, and questions of attitudes and practice sections decreased to 5. The Cronbach's alpha was measured for all three fields and the whole questionnaire; and it was equal to 0.88 for knowledge, 0.87 for attitude,
0.82 for practice, and 0.93 for the whole questionnaire. The normality of distribution of knowledge, attitude, and practice variables was checked by the Kolmogorov-Smirnov test. Data analysis was performed using descriptive statistics as mean and standard deviation, median and interquartile range (IQR) for quantitative variables; and frequency (percentage) for qualitative variables as well as the analytical statistics using MannWhitney and Kruskal-Wallis tests, and generalized linear model using the Gamma probability distribution model due to the abnormal distribution of knowledge, attitude and practice. The variables, namely sex, age, education level, and having a history of underlying disease were included in the generalized linear model relating to the consequence of knowledge; and the sex, age, education level, having an underlying disease, knowledge score were included in the generalized linear model relating to the consequence of attitude; and sex, age, education level, having underlying disease, and attitude score were included in the generalized linear model relating to practice variable; and finally the analysis was performed by SPSS 18.

\section{RESULTS}

A total of 249 individuals answered the questionnaires; and 6 questionnaires were excluded due to incompleteness. Among them, 49.4\% were in the age group of 60-64 years, and $52.2 \%$ were male, and $28.9 \%$ had primary school degrees; $50.2 \%$ had no underlying disease; and $18.3 \%$ had hypertension, $17.9 \%$ had diabetes, $10 \%$ had cardiovascular diseases; $1.2 \%$ had cancer, and $2 \%$ had other diseases, such as kidney and gastrointestinal diseases, and $96.4 \%$ had insurance and pensions. (Tab. I)

The research results indicated that in answer to questions of knowledge, the mean \pm standard deviation of the score (10.8) was 92.3 and it's median (interquartile range (IQR)) (85.7-100) was 100. Most correct answers were to the question "Coronavirus is transmitted through sneezing and coughing" with a value of $75.9 \%$ and the least correct answers were to the question "fever is an important symptom of the disease" with a value of $68.3 \%$. In response to the questions of attitude, the mean \pm standard deviation of the score (14.3) was equal to 89.1; and it's median (interquartile range) (75-100) was 95. The most correct answers were to the question "If I cook my food completely, I will not get infected" with a value of $69.1 \%$ and the least correct answers to the question "Coronavirus infection can be prevented" with a value of $60.2 \%$. In the practice section, the mean \pm standard deviation of the score was equal to $90.4 \pm 13.4$ and it's median (interquartile 
Table I. Some demographic and clinical characteristics of the older people.

\begin{tabular}{|l|c|c|}
\hline \multicolumn{2}{|c|}{ Characteristics } & Frequency (\%) \\
\hline \multirow{4}{*}{ Age } & $60-64$ & $123(49.9)$ \\
\cline { 2 - 3 } & $65-69$ & $44(17.7)$ \\
\cline { 2 - 3 } & $70-74$ & $40(16.1)$ \\
\cline { 2 - 3 } & $75-79$ & $26(10.4)$ \\
\cline { 2 - 3 } & $80-84$ & $9(3.6)$ \\
\cline { 2 - 3 } & $85-89$ & $2(0.8)$ \\
\hline Sex & $90-94$ & $5(2)$ \\
\hline Insurance & Male & $130(52.2)$ \\
\hline Education & Female & $119(47.8)$ \\
\cline { 2 - 3 } & Yes & $240(96.4)$ \\
\cline { 2 - 3 } & No & $67(26.9)$ \\
\cline { 2 - 3 } & Primary school & $72(28.9)$ \\
\cline { 2 - 3 } & Secondary school & $22(8.8)$ \\
\cline { 2 - 3 } & High school diploma & $43(17.3)$ \\
\cline { 2 - 3 } & Associate degree & $20(8)$ \\
\cline { 2 - 3 } & Bachelor & $14(5.6)$ \\
\cline { 2 - 3 } & Master & $11(4.4)$ \\
\hline Underlying disease & Yes & $126(50.6)$ \\
\cline { 2 - 3 } & No & $123(49.4)$ \\
\hline & & \\
\hline
\end{tabular}

range) (75-100) was 100. Most correct answers were to the question "I do not touch my face with my infected hands" with a value of $72.7 \%$; and the least correct answers to the question "I am at least two meters away from others" with a value of $64.3 \%$ (Tab. II).

Table III presents statistical results of relationships between knowledge, attitude, and practice of the older people with some clinical and demographic characteristics such as age, sex, education, and history of underlying diseases about COVID-19 using Mann-Whitney and Kruskal-Wallis tests (univariate) and generalized linear model (multivariate).

According to the results of fitting the generalized linear model, mean scores of knowledge, attitude, and practice of the older people were not significantly different from the sex and history of underlying diseases. In other words, gender and history of underlying disease did not play any role in the knowledge, attitude, and practice of the older people.

There was also no significant relationship between older people's age and their mean scores of knowledge. However, results of the present study indicated that the older people at the age range of 60-64, had no statistically significant mean scores of attitude in comparison with the older people at the age range of older than 80 , but the age ranges of 65-69 and 70-74 had better and statistically significant attitudes than the older people older than 80. The mean scores of the older people practice about Coronavirus in the age range of $75-79$ was not significantly different from the age group above 80 years, but the mean scores of practice in age groups of 60-64, 65-69, and 70-74 were significantly different from the age group above 80 years.

Older people with low levels of education significantly had lower knowledge score percentage than those with higher education, but the results indicated that the mean percentage scores of the older people with bachelor's degrees and higher were not significantly different. It was not true for the means scores of attitude and practice; and there was no statistical difference between different age groups.

\section{DISCUSSION}

The present study investigated the knowledge, attitudes, and practice of the older people about COVID-19; and the research results were useful for health planners in dealing with health crises. Given the population of nearly $10 \%$ of the older people in Iran and the high risk of infection in this age group and the large size of Iran, measuring the knowledge, attitude, and practice of the older people is very important in health planning. According to the research team information, the present study was the first research on this field in Iran although there was no similar study in other countries; hence, it was considered a limitation to a citation from authoritative articles. The present study was conducted about 3 months after the first report of COVID-19 in Iran. During the period, the individuals' knowledge about the disease had increased by conducting extensive training in Iran through audio and video media and cyberspace ${ }^{18,19}$ and the performance of Iran's health system such as follow-up by phone calls from people and follow-up of patients and individuals with chronic diseases such as diabetes and high blood pressure. According to the results of the study, the mean percentage of knowledge was expected to be 92.3, the attitude was 89.1 and the practice was 90.4. Given that about half of the older people suffered from chronic diseases, it can be concluded that the reason for the high mean scores was their understanding of the risk associated with the disease ${ }^{20}$.

The mean score of knowledge was not significantly related to sex, age, and history of underlying diseases in older people, but its mean score was significantly different from the participants' education levels. High scores of the highly educated older people about COVID-19, which was also mentioned in another study, indicated their familiarity with disease causes, transmission, symptoms, and process. Given the participants' answers to questions about ways to transmit the disease (handshakes, 
Table II. Frequency distribution (percentage), Mean \pm standard deviation, and median (interquartile range) of knowledge, attitude, and practice scores of the older people about COVID-19.

\begin{tabular}{|c|c|c|c|c|c|c|}
\hline & \multirow[t]{2}{*}{ Field } & \multicolumn{5}{|c|}{ Frequency (\%) } \\
\hline & & $\begin{array}{l}\text { Totally } \\
\text { agree }\end{array}$ & Agree & No idea & Disagree & $\begin{array}{c}\text { Totally } \\
\text { disagree }\end{array}$ \\
\hline \multirow[t]{7}{*}{ Knowledge } & 1. Coronavirus is transmitted through handshake & $185(74.3)$ & $56(22.5)$ & $5(2)$ & $3(1.2)$ & 0 \\
\hline & $\begin{array}{l}\text { 2. Coronavirus is transmitted through contact with } \\
\text { contaminated objects }\end{array}$ & $184(73.9)$ & $58(23.3)$ & $4(1.6)$ & $3(1.2)$ & 0 \\
\hline & $\begin{array}{l}\text { 3. Coronavirus is transmitted through sneezing and } \\
\text { coughing }\end{array}$ & $189(75.9)$ & $56(22.5)$ & $3(1.2)$ & $1(0.4)$ & 0 \\
\hline & $\begin{array}{l}\text { 4. People who have close contact with patients are at } \\
\text { risk }\end{array}$ & $182(73.1)$ & $64(25.7)$ & $1(0.4)$ & $2(0.8)$ & 0 \\
\hline & $\begin{array}{l}\text { 5. Risk of the disease is higher in people with } \\
\text { underlying diseases (diabetes, cardiovascular and } \\
\text { respiratory diseases) }\end{array}$ & $186(74.7)$ & $52(20.9)$ & $10(4)$ & $1(0.4)$ & 0 \\
\hline & 6. Fever is an important symptom of the disease & $170(68.3)$ & $71(28.5)$ & $4(1.6)$ & $4(1.6)$ & 0 \\
\hline & 7. Patients with mild symptoms should stay at home & $179(71.9)$ & $61(24.5)$ & $3(1.2)$ & $6(2.4)$ & 0 \\
\hline \multicolumn{2}{|c|}{ Mean \pm standard deviation } & \multicolumn{5}{|c|}{$92.3 \pm 10.8$} \\
\hline \multicolumn{2}{|c|}{ Median (interquartile range) } & \multicolumn{5}{|c|}{$100(85.7-100)$} \\
\hline \multirow[t]{5}{*}{ Attitude } & 1. If I cook my food completely, I won't get sick & $172(69.1)$ & $63(25.3)$ & $13(5.2)$ & 0 & $1(0.4)$ \\
\hline & 2. I don't get sick if I stay at home & $162(65.1)$ & $69(27.7)$ & $9(3.6)$ & $8(3.2)$ & $1(0.4)$ \\
\hline & 3. Corona infection is preventable & $150(60.2)$ & $74(29.7)$ & $17(6.8)$ & $8(3.2)$ & 0 \\
\hline & $\begin{array}{l}\text { 4. I don't get sick if I wash my hands with soap and } \\
\text { water }\end{array}$ & $167(67.1)$ & $70(28.1)$ & $7(2.8)$ & $4(1.6)$ & $1(0.4)$ \\
\hline & 5. I don't get infected if I disinfect the surfaces & $169(67.9)$ & $66(26.5)$ & $8(3.2)$ & $6(2.4)$ & 0 \\
\hline \multicolumn{2}{|c|}{ Mean \pm standard deviation } & \multicolumn{5}{|c|}{$89.1 \pm 14.3$} \\
\hline \multicolumn{2}{|c|}{ Median (interquartile range) } & \multicolumn{5}{|c|}{$95(75-100)$} \\
\hline \multirow[t]{5}{*}{ Practice } & $\begin{array}{l}\text { 1. I prevent the disease by disinfecting the surfaces in } \\
\text { the house }\end{array}$ & $172(69.1)$ & $70(28.1)$ & $7(2.7)$ & $2(0.8)$ & 0 \\
\hline & $\begin{array}{l}\text { 2. I will prevent the disease by constantly washing my } \\
\text { hands with soap and water }\end{array}$ & $179(71.9)$ & $65(26.1)$ & $2(0.8)$ & $3(1.2)$ & 0 \\
\hline & $\begin{array}{l}\text { 3. I get a distance of at least two meters away from } \\
\text { others }\end{array}$ & $160(64.3)$ & $68(27.3)$ & $6(2.4)$ & $11(4.4)$ & $4(1.6)$ \\
\hline & 4. I don't touch my face with contaminated hands & $181(72.7)$ & $63(25.3)$ & $2(0.8)$ & $3(1.2)$ & 0 \\
\hline & 5. I wear mask in crowded places & $176(70.7)$ & $57(22.9)$ & $1(0.4)$ & $9(3.6)$ & $6(2.4)$ \\
\hline \multicolumn{2}{|c|}{ Mean \pm standard deviation } & \multicolumn{5}{|c|}{$90.4 \pm 13.4$} \\
\hline \multicolumn{2}{|c|}{ Median (interquartile range) } & \multicolumn{5}{|c|}{$100(75-100)$} \\
\hline
\end{tabular}

contact with contaminated objects, sneezing and, coughing, and close contact with definite patients), it can be concluded that their health behavior against the disease was better ${ }^{16}$ due to the current extensive training, and history of training relating to the fight against influenza in the older people. A significant relationship between participants' education levels and knowledge in the study indicated the possibility of using more diverse educational devices by the older people with higher education, which was consistent with studies conducted in China and Italy in which higher levels of education were associated with participants' higher knowledge ${ }^{3,18}$. A study in Sudan indicated decreasing the access to the Internet weakened the individuals' knowledge, attitudes and, practice of people at risk, especially the older people about COVID-19 ${ }^{19}$. In Italy, the participants' knowledge also increased as their education levels increased ${ }^{3}$. In a study by Abdelhafiz et al. in Egypt, the knowledge levels of the older people about COVID-19 were lower than the average ${ }^{21}$ probably due to the lower or no access to the Internet that was a factor in the lack of knowledge about the disease ${ }^{22}$, while in a Malaysian study, the knowledge scores of individuals over 50 years of age were higher due to the greater understanding of the disease ${ }^{23}$. In Singapore, the older people's rate of knowledge about influenza and the need for vaccination against it was reported to be low ${ }^{24}$.

The findings of the present study indicated the participants' high attitude in the study about COVID-19. The older people's attitude in the present study also obtained 
Table III. Statistical results of relationships of knowledge, attitude and practice of the older people with some demographic and clinical characteristics of COVID-19 using Mann-Whitney and Kruskal-Wallis tests (univariate) and the generalized linear model (multivariate).

\begin{tabular}{|c|c|c|c|c|c|c|c|}
\hline & & \multicolumn{2}{|c|}{ Knowledge* } & \multicolumn{2}{|c|}{ Attitude** } & \multicolumn{2}{|c|}{ Practice $^{\star \star *}$} \\
\hline & & Mean (sd) & Median (IQR) & Mean (sd) & Median (IQR) & Mean (sd) & Median (IQR) \\
\hline \multirow[t]{2}{*}{ Sex } & Female & $92(11)$ & $100(82.1-100)$ & $88.9(15)$ & $95(75-100)$ & $90.2(13.3)$ & $100(75-100)$ \\
\hline & Male & $92.5(10)$. & $96.4(88.4-100)$ & $89.5(13.6)$ & $95(75-100)$ & $90.6(13.5)$ & $100(75-100)$ \\
\hline \multirow[t]{2}{*}{ Significance level } & Mann Whitney & \multicolumn{2}{|c|}{0.764} & \multicolumn{2}{|c|}{0.866} & \multicolumn{2}{|c|}{0.505} \\
\hline & $\begin{array}{l}\text { Generalized linear model } \\
\text { (reference: male) }\end{array}$ & \multicolumn{2}{|c|}{0.204} & \multicolumn{2}{|c|}{0.126} & \multicolumn{2}{|c|}{0.746} \\
\hline \multirow[t]{5}{*}{ Age } & $60-64$ & $92.3(10.7)$ & $96.4(85.7-100)$ & $88(14.9)$ & $95(75-100)$ & $90.1(12.8)$ & $100(88-100)$ \\
\hline & $65-69$ & $93.8(10.3)$ & $100(92.3-100)$ & $93.8(9.7)$ & $100(90-100)$ & $94(10)$ & $100(87.5-100)$ \\
\hline & $70-74$ & $92.4(10.2)$ & $98.2(84-100)$ & $90.1(13.5)$ & $100(75-100)$ & $92(12.8)$ & $100(76.3-100)$ \\
\hline & $75-79$ & $92.3(10.6)$ & $100(82.1-100)$ & $91.3(11.8)$ & $95(78.8-100)$ & $89(13.2)$ & 75 (66.3- 95) \\
\hline & $\leq 80$ & $87.7(14.5)$ & $91(75.9-100)$ & $77.8(19.3)$ & $75(67.5-100)$ & $75.3(18.5)$ & 75 (66.3- 95) \\
\hline \multirow[t]{2}{*}{ Significance level } & Kruskal-Wallis test & \multicolumn{2}{|c|}{0.659} & \multicolumn{2}{|c|}{0.020} & \multicolumn{2}{|c|}{0.001} \\
\hline & $\begin{array}{l}\text { Generalized linear model } \\
\text { (Reference: age over 80) }\end{array}$ & \multicolumn{2}{|c|}{$\begin{array}{l}0.491 \\
0.328 \\
0.368 \\
0.349\end{array}$} & \multicolumn{2}{|c|}{$\begin{array}{l}0.114 \\
0.015 \\
0.033 \\
0.015\end{array}$} & \multicolumn{2}{|c|}{$\begin{array}{l}0.007 \\
0.012 \\
0.011 \\
0.109\end{array}$} \\
\hline \multirow[t]{3}{*}{ Education level } & Secondary school and lower & $90.1(12.1)$ & $96.4(75-100)$ & $87(15.7)$ & $95(75-100)$ & $87.7(14.4)$ & $100(75-100)$ \\
\hline & $\begin{array}{l}\text { High school diploma and } \\
\text { associate degree }\end{array}$ & $96.1(6.6)$ & $100(96.4-100)$ & $93(11)$ & $100(90-100)$ & $93.7(11.3)$ & $100(90-100)$ \\
\hline & Master and higher & $96.7(5.3)$ & $96.4(96.4-100)$ & $93.4(8.6)$ & $95(90-100)$ & $93.2(8.6)$ & $100(87.5-100)$ \\
\hline \multirow[t]{2}{*}{ Significance level } & Kruskal-Wallis test & \multicolumn{2}{|c|}{0.018} & \multicolumn{2}{|c|}{0.045} & \multicolumn{2}{|c|}{0.111} \\
\hline & $\begin{array}{l}\text { Generalized linear model } \\
\text { (Reference: master degree } \\
\text { and higher) }\end{array}$ & \multicolumn{2}{|c|}{$\begin{array}{l}0.001 \\
0.728\end{array}$} & \multicolumn{2}{|c|}{$\begin{array}{l}0.720 \\
0.797\end{array}$} & \multicolumn{2}{|c|}{$\begin{array}{l}0.860 \\
0.802\end{array}$} \\
\hline \multirow{2}{*}{$\begin{array}{l}\text { Underlying } \\
\text { disease }\end{array}$} & Yes & $93.2(9.8)$ & $100(89.3-100)$ & $90.1(11.6)$ & $95(78.8-100)$ & $91.7(11.7)$ & $100(80-100)$ \\
\hline & No & $91.3(11.8)$ & $\begin{array}{c}96.4(82.1- \\
100)\end{array}$ & $87.4(16.5)$ & $95(75-100)$ & $89(14.8)$ & $100(75-100)$ \\
\hline \multirow[t]{2}{*}{ Significance level } & Mann Whitney & \multicolumn{2}{|r|}{0.261} & \multicolumn{2}{|c|}{0.448} & \multicolumn{2}{|c|}{0.381} \\
\hline & $\begin{array}{l}\text { Generalized linear model } \\
\text { (Reference: no underlying } \\
\text { disease) }\end{array}$ & \multicolumn{2}{|c|}{0.249} & \multicolumn{2}{|c|}{0.099} & & 926 \\
\hline
\end{tabular}

*: Sex, age, education level, and history of underlying diseases were used to fit the model; **: Sex, age, education level, and history of underlying diseases and knowledge score were used to fit the model; ***: Sex, age, education level, and history of underlying diseases and attitude score were used to fit the mode

a score of 89.1 indicating the participants' high knowledge in the study ${ }^{25}$. The participants' attitude scores were also high in different studies ${ }^{18,19,25}$. The mean scores of attitude had no significant relationship with participants' sex and history of underlying diseases in the study, while the participants' attitude scores had significant differences in different age groups.

$94.37 \%$ of the participants believed in staying at home to prevent the disease, which was consistent with a study in China (96.4\%) and a study in Sudan (96.9\%) $((18,19))$. In a study by Aziz et al. in Egypt, having a proper understanding of the risks of infectious diseases in Hajj rituals predicted the health search behavior among participants ${ }^{26}$. In a study in Singapore, poor older people's knowledge about influenza vaccination led to a misunderstanding of the subject and a lack of vaccination ${ }^{24}$.

Despite the participants' desirable levels of overall practice scores, which were correlated with scores of knowledge and attitude, their practice in some cases such as observing the appropriate distance (2 meters) from others was $64.3 \%$ of cases and it was consistent with findings of a study in China. In the same study, the participants had high scores due to their high knowledge as well as precise control measures by the Chinese government ${ }^{18}$. According to the comparison of the age and practice of the age group, the older people aged 60 to 74 had a higher practice score than the older age group that can be attributed to the physical conditions and better health of the age group. 


\section{RESEARCH LIMITATIONS}

Lack of articles relating to the research subject in the older people and the lack of random sampling among the older people under the coverage of health centers due to the spread of the disease and the legal prohibition of inviting the older people were among the limitations of the present study.

\section{CONCLUSIONS}

The present paper indicated the knowledge, attitude, and practice of the older people living in Isfahan that can help health policy makers to plan health care to deal with the COVID-19 pandemic crisis. To this end, a relevant questionnaire was developed and the effect of the disease on the knowledge, attitude, and practice of the older people was measured. A significant point in the results of the present study was an increase in the level of knowledge in older people with an increase in their education levels, indicating the higher ability to use mass media and social networks. Furthermore, older people's attitude and performance scores had a significant relationship in different age groups and were affected by their levels of knowledge. The results indicated the need for the health system to attempt to increase the public knowledge of the older people to improve their attitude and practice to deal with the crisis.

\section{ACKNOWLEDGMENTS}

We are grateful to all the older people and questioners who cooperated in the present study.

\section{References}

1 Jin J-M, Bai P, He W, et al. Higher severity and mortality in male patients with COVID-19 independent of age and susceptibility. medRxiv 2020. https://doi.org/ 10.3389/ fpubh.2020.00152

2 Chan JF-W, Yuan S, Kok K-H, et al. A familial cluster of pneumonia associated with the 2019 novel coronavirus indicating person-to-person transmission: a study of a family cluster. Lancet 2020;395:514-23. https://doi.org/10.1016/ S0140-6736(20)30154-9

3 Motta Zanin G, Gentile E, Parisi A, et al. A preliminary evaluation of the public risk perception related to the COVID-19 health emergency in Italy. Int J Environ Res Public Health 2020;17:3024. https://doi.org/10.3390/ijerph17093024

4 I.R.I MoHo 2020.

5 WHO. WHO coronavirus disease (COVID-19) Dashboard 2020 (https://covid19.who.int).

6 Lipsitch M, Swerdlow DL, Finelli L. Defining the epidemiology of COVID-19 - studies needed. N Engl J Med 2020. https://doi.org/ 10.1056/NEJMp2002125 [Epub ahead of print]

7 Heymann DL, Shindo N. COVID-19: what is next for public health? Lancet 2020. https://doi.org/10.1016/S01406736(20)30374-3 [Epub ahead of print]

8 Guan W-j, Ni Z-y, Hu Y, et al. Clinical characteristics of 2019 novel coronavirus infection in China. MedRxiv 2020. https://doi.org/10.1101/2020.02.06.20020974

9 Yan Y, Shin WI, Pang YX, et al. The first 75 days of novel coronavirus (SARS-CoV-2) outbreak: recent advances, prevention, and treatment. Int J Environ Res Public Health 2020;17:2323. https://doi.org/n10.3390/ijerph17072323

10 Alanzi ME, Albalawi MAH, Kabrah S, et al. Knowledge, Attitudes, and Practices (KAPs) of healthcare workers towards MERS-CoV infection at PHCs in Madinah, KSA during Hajj 1440, 2019. Am J Microbiol Res 2019;7. https:// doi.org/10.12691/ajmr-7-4-4

11 Slovic P. Perception of risk. Science (New York, NY). 1987;236:280-5.

12 Krewski D, Slovic P, Bartlett S, et al. Health risk perception in Canada I: Rating hazards, sources of information and responsibility for health protection. Hum Ecol Risk Assess 1995;1:117-32.

13 Kempinski R, Krasnik A. Prevention of arteriosclerotic heart disease. An epidemiological study of knowledge, attitudes and practices in a community in Israel. Ugeskrift Laeger. 1974;136:1931-8.

14 Suleiman M, Sahal N, Sodemann M, et al. Tuberculosis awareness in Gezira, Sudan: knowledge, attitude and practice case-control survey. EMHJ 2014;20:120-9.

15 Terán Calderón C, Gorena Urizar D, González Blázquez C, et al. Knowledge, attitudes and practices on HIV/AIDS and prevalence of HIV in the general population of Sucre, Bolivia. Braz J Infect Dis 2015;19:369-75. https://doi. org/10.1016/j.bjid.2015.04.002

16 Lin Y, Huang L, Nie S, et al. Knowledge, attitudes and practices (KAP) related to the pandemic (H1N1) 2009 among Chinese general population: a telephone survey. BMC Infect Dis 2011;11:128. https://doi.org/10.1186/14712334-11-128

17 Chou W-YS, On A, Klein WM. Addressing health-related misinformation on social media. Jama 2018;320:2417-8. https://doi.org/10.1001/jama.2018.16865

18 Zhong B-L, Luo W, Li H-M, et al. Knowledge, attitudes, and practices towards COVID-19 among Chinese residents during the rapid rise period of the COVID-19 outbreak: a quick online cross-sectional survey. Int J Biol Sci 2020;16:1745. https://doi.org/10.7150/ijbs.45221

19 Mousa KNAA, Saad MMY, Abdelghafor MTB. Knowledge, attitudes, and practices surrounding COVID-19 among Sudan citizens during the pandemic: an online cross-sectional study. Sudan J Med Sci 2020. https://doi. org/10.18502/sjms.v15i5.7176 [Epub ahead of print]

20 Ajzen I. The theory of planned bahavior. Organ Behav Hum Dec Proc 1991;50.

21 Abdelhafiz AS, Mohammed Z, Ibrahim ME, et al. Knowledge, perceptions, and attitude of egyptians towards the 
novel coronavirus disease (COVID-19). J Comm Health 2020:1-10. https://doi.org/10.1007/s10900-020-00827-7

22 Newman MG, Zainal NH. The value of maintaining social connections for mental health in older people. Lancet Public Health 2020;5:e12-3. https://doi.org/10.1016/S24682667(19)30253-1

23 Azlan AA, Hamzah MR, Sern TJ, et al. Public knowledge, attitudes and practices towards COVID-19: a crosssectional study in Malaysia. Plos One 2020;15:e0233668. https://doi.org/10.1371/journal.pone.0233668

24 Cummings CL, Kong WY, Orminski J. A typology of beliefs and misperceptions about the influenza disease and vaccine among older adults in Singapore. PloS One 2020;15:e0232472. https://doi.org/10.1371/journal. pone.0232472

25 Shi Y, Wang J, Yang Y, et al. Knowledge and attitudes of medical staff in Chinese psychiatric hospitals regarding COVID-19. Brain Behav Immun-Health 2020:100064. https://doi.org/10.1016/j.bbih.2020.100064

26 Aziz MM, Abd El-Megeed HS, Abd Ellatif MAM. Pre-travel health seeking practices of Umrah pilgrims departing from Assiut International Airport, Egypt. Travel Med Infect Dis 2018;23:72-6. 